\title{
The Relationship Between Home Literacy Environment and Teenagers' Reading Habits
}

\author{
Deng Qiuchi ${ }^{1, a, \dagger}$, Xin Yuxin $^{2, b, \dagger}$ \\ ${ }^{1}$ School of Geography, South China Normal University, Guangzhou, Guangdong 510000, China; \\ ${ }^{2}$ School of Art Design and Media, East China University of Science and Technology, Shanghai 200000, China. \\ a qiuchideng@m.scnu.edu.cn, ${ }^{b} 10181082 @$ mail.ecust.edu.cn \\ These authors contributed equally.
}

\begin{abstract}
Reading is a kind of significantly positive behaviour for teenagers, especially since it may improve their academic intelligence and emotional intelligence. The home literacy environment is related to the reading habits, while the study about the reading habits of teenagers is still limited. This paper focuses on the relationship between home literacy environment and teenagers' reading habits, as well as discusses the impact of home literacy environment on teenagers' reading habits, the thematic relationship across different culture, and socioeconomic status and gender differences in the relationship. According to existing research, this study reveals that home literacy has positive influence on adolescents' reading habit. However, the relationship between home literacy environment and reading habits is not always influenced by cultural differences or socioeconomic status, and there are differences in reading habits between female teenagers and male teenagers.
\end{abstract}

Keywords: Home literacy environment, Teenagers' reading habit, Family education, Cross-culture, Socioeconomic status, Gender differences

\section{INTRODUCTION}

Home literacy environment (HLE) is a literacy activity engaged by parents with children (i.e., parent's reading behaviours, books at home, and communication about books between families) [1]. Reading has essential and important influence on the growing and developing process of people [2], especially with the technology developing in leaps and bounds. Reading can help students understand massive information and gain skills such as critical thinking and sustainable creativity, so that they can adapt the social development and have opportunities to enter top universities, get well-paid jobs, and make more contribution to our society. Reading habit is a routine reading that is long-standing. To develop the reading habit, children's reading skills are also needed to be improved [3]. Home literacy environment may be meaningful for children to improve literacy and reading skills during their academic years [4]. People's brain system has diverse changes in adolescence defined as age 12 to age 18, which causes a series of shifts in the methods of processing, integrating, and retaining information with lifelong impact on learning [5]. Reading is a kind of positive and beneficial factor for the better development of teenagers. Therefore, we cannot ignore the importance of the reading behaviour of adolescence.

Sénéchal improved the Home Literacy Model [6], and the researcher focused on the vertical relationship in home literacy experiences including parental book reading, literacy teaching, and different literacy skills of children (e.g., reading and spelling skills, reading comprehension and fluency). According to this study, it was predicted by Home Literacy Model that reading book had direct relationship with children's language ability such as reading and printing words. In addition, children's early literacy skills were influenced by parental literacy teaching directly, while there was indirect relationship between parents' teaching and children's phoneme awareness and no relationship between parents' teaching and vocabulary learning. Storybook reading was related to more advanced reading skills in primary school indirectly. There was another study focused on pre and early school children as well [1]. It showed that many parents had relatively fewer home literacy activities such as shared book reading with their children as they were older. However, the involvement of parents in home literacy activities could help their children who were able to read independently to have 
better reading abilities and long-time positive reading attitude. In addition, children's reading behaviour had influence on their home literacy environment, because parents were able to perceive children's reading interest and adjust their frequency of home literacy activities according to that. Therefore, there might be an interactive relationship between parents' and children's reading behaviour.

As mentioned above, there are numerous studies on the relationship between home literacy environment (HLE) and reading interest, as well as reading development of preschool children and primary school students. Reading books at early stage directly influences children's language ability. In addition, parental literacy teaching directly influences children's early literacy skills, while storybook reading indirectly leads to more advanced reading skills at the primary stage. As is known, childhood is a vital period in which children's personalities are formed and children's brains are developed [7]. And adolescence is also a sensitive period to children's growth, but studies that investigate the relationship between adolescents' reading habit and their home literacy environment are scarce. So, this review emphasizes the impact that HLE has on children's later stage. Moreover, more in-depth exploration will be conducted on whether culture differences have effect on this association. This review aims to evaluate the following factors at the same time, including family socioeconomic status (SES) and gender differences.

\section{THE IMPACT OF HLE TO READING DURING ADOLESCENCE}

Previous studies have shown that the average time that parents spent reading to a young child (of between 15 and 60 months old) had a positive direct effect on reading motivation in childhood and adolescence [8]. In the study conducted by Boerma and his colleagues, they used the questionnaire to investigate how home literacy environment influenced children's (Grade 4-6) reading interest. Parents were asked about their reading habits and enjoyment on a four-point Likert scale. To evaluate children's self-reported reading interest, they were asked some related questions (e.g., how do you feel when you read a book on a rainy Saturday?). It showed that home literacy environment was significantly related to the reading interest of children and have a positive effect on that [9]. Children whose parents participated more in home literacy activities self-reported higher reading interest. It's worth noting that children's reading interest was related to the frequency of home literacy activities, and when parents both buy books and read for them, the likelihood of a student taking an interest in reading is the highest [10-12]. Interestingly, it was found that parents whose children were interested in reading, but who were not interested readers themselves, adjusted themselves and still engaged in literacy activities at home, same as those parents who were interested readers. Also, the impact that HLE has on children's reading interest is sustainable and long-term, so when they are adolescents, their reading may still be influenced by their early home literacy environment.

The sustainability of the impact that home literacy environment has on teenagers' reading habits was also discussed in Notten and Becker's study [2]. They conducted a study to find the relationship between early home literacy and adolescents' online reading behaviour. It shows that an early home literacy environment may influence children's online reading behaviour and skills during adolescence positively. Questionnaires are used in this study. Parents were asked how often they or other family members take part in family activities (e.g., telling stories, reading aloud signs and labels) during children' s first year of education. A mediation analysis shows that teenagers ' reading skills, reading behaviour, and attitude toward reading together significantly mediate the effect of the early home literacy environment on adolescents' online reading behaviour. Moreover, there is a positive relationship between students' early offline reading frequency and their informational online reading behaviour, which indicates that those students who are better and more frequent offline readers in early age, and who have a positive attitude toward reading, are also more avid online informational readers. Hence, the early home literacy environment is not a short-term influence factor, but a sustainable one.

Home literacy environment is related to parental education level to some extent. Compared with parents with a high level of education, those who received less education pay relatively less attention to children's learning, which causes that the quality of the home literacy environment is not good enough to develop children's reading skills and habits. And some researches have a similar conclusion. In Notten's study [2], they used the main data of 15-year-olds from the 2009 OECD PISA and country-level fixed effects models. According to the study, parental education level has a positive and direct correlation with students' online reading behaviour, and those families with higher educational levels and books are more likely to develop students' reading interests. Parental cultural capital which includes their educational level and a number of books at home has influence on early parental reading socialization which is positively and directly related to students' online reading; at the same time, the study shows that students who are good at online reading are more likely be a better offline reader as well. Therefore, parental cultural capital influences adolescents' reading habits. In addition, if parents both buy books for adolescents and read together with them, pupils may have more interest in reading and optimal opportunity to form reading habits [13]. Thus, we may need to focus on parental reading attitude in some 
cases to develop parents' awareness of reading at first, so that they will adjust their home literacy environment to encourage their children to read more.

\section{THE RELATIONSHIP BETWEEN HLE AND READING HABITS ACROSS DIFFERENT CULTURES}

The external environment will build teenagers' habits of reading, which includes social environment and home literacy environment; therefore, the cultural environment can foster different educational opinions. In eastern countries, parents tend to make lots of plans for children's development; for instance, Chinese parents pay great attention to their children's education, and with the fierce social competition both for junior- high school and high school students, parents intervene in kinds of things in students' study to make sure that they have chances to enter the elite schools [14]. In other words, eastern parents tend to arrange pupils' education in many cases. Compared with that, families living with western culture are more likely to have less intervention and let children develop in individuation [15]. With this relative difference, it is intriguing to find out that whether eastern countries' families have better home literacy than that of western families.

Whereas, we can find that the family reading is also valued in some western areas. In England, according to Clark and Foster's study about pupils in age 6 to age 16 [16], which used questionnaires including their reading habits, behaviours, and attitude, the majority of students' mother had taught them how to read and encouraged them to read, which had the largest proportion followed by that of teachers; at the same time, most students reported that people chosen to discuss reading with were their parents. Participants also believed that one of the main parts of teaching reading is family education. Therefore, students in England are influenced by their reading habits by home-schooling generally. Even though they may show the tendency which is that they prefer to act by themselves instead of with family in many cases, people in western countries are willing to create home literacy environment to develop their children's reading habits.

Compared with western countries, there is a study about home literacy environment and pre-schoolers' reading in China, which shows the different characteristics of Chinese home literacy activities. Zhang and her colleagues combined with the home literacy model and focused on informal literacy and formal literacy respectively [17]. Informal literacy activities are the time when children have activities like book sharing and print incidentally, and formal literacy activities are the time when children learn to print directly; Interestingly, children can gain more vocabulary from informal literacy experiences [6]. In the study, participants were Chinese children who were around 6 years old and their parents; and children were tested in word reading, and the parents filled out a questionnaire about their educational and economic level, the frequency of their shared book reading, the number of books at home and so on. According to the study by Zhang, literacy resources at home can make children have more reading motivation and predict children's informal literacy experiences as well; at the same time, parental expectations have a long-term relationship with children's reading outcomes, and Chinese parents are more likely to focus on children's academic achievement [18], which may also have a positive influence on children's reading habits. However, researchers point out that Chinese informal literacy, which has a close association with family education, is not taken seriously enough; Therefore, Chinese parents not only need to rich literacy resources for children, but also need to pay more attention to shared book reading at home. Hence, although some eastern countries value home literacy environment, some parents neglect the correct guidance for children reading habits.

We can find that family education with different cultural backgrounds all have attention on the development of children's reading habits, and there is still the relationship between home literacy environment and reading habits, even though parents may not have similar forms and methods in home literacy environment owing to their own culture. In addition, parent-child reading is one of the significant ways to improve teenagers' reading interest and habits, which is not related to cultural differences obviously; therefore, most parents should keep shared book reading with children at home.

\section{SES AND GENDER DIFFERENCES IN THE RELATIONSHIP BETWEEN HLE AND READING HABITS}

Socioeconomic background and its relationship with the reading habits of students is one of the enduring issues in educational research [19]. According to statistics from PISA 2009 of Australia, 33\% of students of the lowest SES quartile claimed they did not read for enjoyment, while the proportion decreased to $17 \%$ when it comes to the highest SES quartile [20]. Students from low SES families have fewer chances to read books because they need to help in their family, such as doing chores and they don't have enough resources. We can't deny that those upper-class parents or the rich parents tend to spend more on children's reading resources (e.g., books, educational games, laptop as well as on extracurricular courses) [21,22], and provide more opportunities to read, as a result, it seems that their children are more likely to come into contact with better reading habits, compared to their peers. However, in most cases, rich people spend more time and energy on their careers, thus having less time to company with their children. According to a study conducted by Le, et al., adolescents with high SES are more likely to buy books, while the children with the poor 
background can still obtain books, they want by borrowing [23]. The study report that students from rich families were most likely to buy books and least were likely to receive them as gifts $(5.9 \%$ and $12.9 \%$ in case of having a reading interest or not respectively), out of all the means of access to books listed in the survey. The situation is the same when it comes to students from medium families. However, students not obtaining a wealthy background tend to borrow books with a likelihood of more than $60 \%$ [23]. This difference between these two groups is not related to reading interest and reading habits. So, the correlation between SES and adolescents' reading habits is not always consistent.

Gender differences have also been examined in relation to reading habits. Research studies in both Western and Eastern societies have shown that males and females are often reported to differ significantly in reading enjoyment, motivation, and reading material preferences [16,24-27]. According to a study conducted by Tran, et al., females are more likely to have interests in reading than males [13]. The study shows male students are less likely to report that they like reading (82-89\%), while female students whose hobby is reading is $99.2 \%$. For reading motivation, female students read for social purposes, while male students read more for tasks (e.g., not for pleasure) [28]. Moreover, male students and female students have different preferences in hobbies and reading materials. In Tran's study, boys tend to be affected by the high sensory stimulation (e.g., socializing with friends, watching TV/listening to music), while girls are more likely to be influenced by low sensory stimulation like reading, observing nature, and helping with chores [13]. As for reading materials, it has been proved that males prefer reading newspapers, literature, and web site than girls do [24]. Not only the children's gender but also the different gender of mother and father have an impact on the association of HLE and adolescents' reading habits.

Joó and Dani conducted a study which discussed whether parental reading behaviour explained the gender differences in adolescents' reading attitude [28]. It suggests that female students are generally more influenced by home literary environment and have more desire to read if either parent has positive reading behaviour. As mentioned above, girls prefer reading than boys do, one reason may be that boys don't value reading that much as girls do. They regard reading as a feminine activity because they see female relatives and teachers read more frequently than males in their family and school [29]. Questionnaires are used in Joó and Dani's study to investigate how home literacy environment influences offspring's reading attitude and explain the differences in this regard between girls and boys. The questionnaires involve the reading preference, the frequency, and the reading time of the participants. It indicates that fathers' paper-based reading has an impact on both male and female adolescences' reading motivation, however, mothers' paper-based reading only contributes to girls' reading attitude. The girls read for social interaction, while boys read more for tasks. Also, girls' motivation proved to be more affected by parental reading frequency, while boys' motivation did not. According to the study, both parents' reading preferences on reading materials have an impact on children while the impact of mothers' reading preferences is in larger areas. It demonstrates that children whose mothers are long story readers are represented among long story readers in a higher percentage $(65 \%)$ than those whose mothers do not $(58 \%)$.

\section{LIMITATION AND FUTURE DIRECTION}

Studies we mentioned above showed us the correlation between home literacy environment and teenagers' reading habits but there are still some questions that remain to be solved. First, we know that different cultures can influence the home literacy environment from the present studies. However, we don't have the concrete contrast between two or more counties directly. Future studies can focus on eastern and western culture the whole study, and find out how these different cultures affect the home literacy environment in detail. Moreover, the research about gender differences was conducted at a certain age of the teenagers, so the results only reflected the impact of that age. If we really want to find how gender differences influence teenagers' reading habits, we should conduct longitudinal research to present the dynamic change of that period. In this way, we can know in which stage fathers influence more on children's reading habits and in which stage mothers' do so that parents can adjust themselves and modify their teaching patterns and home literacy environment. Moreover, most of the study shows the correlation between HLE and teenagers' reading habits. If we are going to find out the further and accurate relationship between these two elements, we should know whether they have a causal relationship. It is suggested that people who will do the research can conduct an experiment instead of a questionnaire. They can recruit two groups of parents whose children are at the same age in one country at the same time. One group will remind the importance of home literacy environment and the other group won't. In this way, we can see whether better home literacy environment can result in teenagers' better reading habits.

\section{CONCLUSION}

This paper tries to give an account of the relationship between home literacy environment and adolescents' reading habits. Additionally, this paper discusses three main topics including the influences of home literacy environment on adolescents' reading, the relationship between home literacy environment and reading habits with different cultures, and socioeconomic status and 
gender differences in this relationship. Firstly, it is found that home literacy environment, which is related to parental cultural capital, has significant impact on adolescents' reading behaviour. For example, the higher the frequency of shared book reading at home is, the higher the teenagers' reading motivation is. Secondly, cultural differences may have influence on family education forms, but the relationship between home literacy environment and reading habits always exists. In addition, it is shown that, parents in western culture will read more books for children more than the oriental parents. Thirdly, the correlation between the socioeconomic status of family and the reading habits of adolescents is not always consistent. Finally, as for gender differences in reading, adolescents with different genders have different reading hobbies. Moreover, female teenagers may have more interest in reading than males and are influenced by home literacy environment more as well.

Indeed, more research in our study is needed to have more case supports and more specific explanation between the home literacy environment and the reading habits of adolescents. To provide more effective suggestions for the development of teenager reading habit through adjusting home literacy environment, it would be beneficial to replicate this study with larger and different cases and samples.

\section{REFERENCES}

[1] Boerma, I. E., Mol, S. E., Jolles, J. (2018). Parents adjust the quality of their home literacy environment to the reading interest of their third to sixth graders. Parenting, 18(4), 243-261.

[2] Notten, N., Becker, B. (2017). Early home literacy and adolescents' online reading behavior in comparative perspective. International Journal of Comparative Sociology, 58(6),475-493.

[3] Mansor, A. N., Rasul, M. S., Abd Rauf, R. A., \& Koh, B. L. (2013). Developing and sustaining reading habit among teenagers. The Asia-Pacific Education Researcher, 22(4), 357-365.

[4] Boulhrir, T. (2017). Using Binary Logistic Regression to Predict Long-Term Effects of Early-Age Home Literacy Environment on Reading Motivation. American Journal of Educational Research, 5(8), 858-862.

[5] Dahl, R. E., Allen, N. B., Wilbrecht, L., Suleiman, A. B. (2018). Importance of investing in adolescence from a developmental science perspective. Nature, 554(7693),441-450.

[6] Sénéchal, M. (2006). Testing the home literacy model: Parent involvement in kindergarten is differentially related to grade 4 reading comprehension, fluency, spelling, and reading for pleasure. Scientific studies of reading, 10(1), 59-87.

[7] Shonkoff, J. P., Garner, A. S., Siegel, B. S., Dobbins, M. I., Earls, M. F., McGuinn, L., ... \& Committee on Early Childhood, Adoption, and Dependent Care. (2012). The lifelong effects of early childhood adversity and toxic stress. Pediatrics, 129(1), e232e246.

[8] Gottfried, A. W., Schlackman, J., Gottfried, A. E., \& Boutin-Martinez, A. S. (2015). Parental provision of early literacy environment as related to reading and educational outcomes across the academic lifespan. Parenting, 15(1), 24-38.

[9] Baker, L., \& Scher, D. (2002). Beginning reading readers' motivation for reading in relation to parental relation to parental beliefs and home reading experiences. Reading psychology, 23(4), 239-269.

[10] Bracken, S. S., \& Fischel, J. E. (2008). Family reading behavior and early literacy skills in preschool children from low-income backgrounds. Early Education and Development, 19(1), 45-67.

[11] Lyytinen, P., Laakso, M., \& Poikkeus, A. (1998). Parental contribution to child's early language and interest in books. European Journal of Psychology of Education, 13(3), 297-308.

[12] Weigel, D. J., Martin, S. S., \& Bennett, K. K. (2006). Contributions of the home literacy environment to preschool-aged children's emerging literacy and language skills. Early Child Development and Care, 176(3-4), 357-378.

[13] Tran, T., Le, T. T. H., Nguyen, T. T., Pham, A. G., Vu, T. H., Nguyen, M. H., ... \& Vuong, Q. H. (2019). The relationship between birth order, sex, home scholarly culture and youths' reading practices in promoting lifelong learning for sustainable development in Vietnam. Sustainability, 11(16), 4389.

[14] Zhu, M. (1999). The views and involvement of Chinese parents in their children's education. Prospects, 29(2), 233-238.

[15] Di Paola, B. (2016). Why Asian children outperform students from other countries? Linguistic and parental influences comparing Chinese and Italian children in Preschool Education. International Electronic Journal of Mathematics Education, 11(9), 3351-3359.

[16] Clark, C., \& Foster, A. (2005). Children's and Young People's Reading Habits and Preferences: The Who, What, Why, Where and When. National Literacy Trust. 
[17] Zhang, S. Z., Inoue, T., Shu, H., \& Georgiou, G. K. (2019). How does home literacy environment influence reading comprehension in Chinese? Evidence from a 3-year longitudinal study. Reading and Writing, 1-23.

[18] Lu, Y. (1999). Nice family atmosphere is the precondition and basis of education. Family Education, 147, 1-12. [in Chinese].

[19] Thomson, S. (2018). Achievement at school and socioeconomic background-an educational perspective. npj Science Learn, 3, 5.

[20] Thomson, S.; De Bortoli, L.; Nicholas, M.; Hillman, K.; Buckley, S. (2010). Challenges for Australian Education: Results from PISA 2009: The PISA 2009 Assessment of Students' Reading, Mathematical and Scientific Literacy. Melbourne, Australia: ACER Project Publishing Department.

[21] Çiftçi, Ş. K., \& Cin, F. M. (2017). The effect of socioeconomic status on students' achievement. The factors effecting student achievement, 171-181.

[22] Sirin, S.R. (2005). Socioeconomic Status and Academic Achievement: A Meta-Analytic Review of Research. Review of educational research, 75(3), 417-453.

[23] Le, T. T. H., Tran, T., Trinh, T. P. T., Nguyen, C. T., Nguyen, T. P. T., Vuong, T. T., ... \& Vuong, Q. H. (2019). Reading habits, socioeconomic conditions, occupational aspiration and academic achievement in Vietnamese junior high school students. Sustainability, 11(18), 5113.

[24] Karim, N. S. A., \& Hasan, A. (2007). Reading habits and attitude in the digital age: Analysis of gender and academic program differences in Malaysia. The Electronic Library.

[25] Majid, S., \& Tan, V. (2007). Understanding the Reading Habits of Children in Singapore. Journal of Educational Media \& Library Sciences, 45(2).

[26] Moffitt, M. A. S., \& Wartella, E. (1991). Youth and reading: A survey of leisure reading pursuits of female and male adolescents. Reading Research and Instruction, 31(2), 1-17.

[27] Topping, K. J., Samuels, J., \& Paul, T. (2008). Independent reading: The relationship of challenge, non - fiction and gender to achievement. British Educational Research Journal, 34(4), 505-524.

[28] Joó, A., \& Dani, E. May parental reading behavior explain the gender differences in subteeners' reading attitude?. Systemics, Cybernetics and Informatics, 16(2), 17-21.
[29] Logan, S., \& Johnston, R. (2009). Gender differences in reading ability and attitudes: examining where these differences lie. Journal of Research in Reading, 32(2), 199-214. 